\title{
Organizing for thoughtful food: a meshwork approach
}

\author{
Kathryn Pavlovich ${ }^{1}$ (D) Alison Henderson ${ }^{1} \cdot$ David Barling $^{2}$
}

Accepted: 31 July 2020 / Published online: 8 August 2020

(c) Springer Nature B.V. 2020

\begin{abstract}
This paper provides an alternative narrative for organizing food systems. It introduces meshwork as a novel theoretical lens to examine the ontological assumptions underlying the shadow and informal dynamics of organizing food. Through a longitudinal qualitative case study, we place relationality and becoming at the centre of organizing food and food systems, demonstrating how entangled relationships can create a complex ontology through the meshwork knots, threads and weave. We show how issues of collective concern come together to form dynamic knots of interactions, how the threads within the meshwork indicate processes of movement, and how the weave suggests degrees of food system resilience—but always in flow. This theoretical approach thus provides a platform for addressing thoughtful concerns about "food matters" including the integrity of our global food system, the negative health and environmental impacts of industrialized food production, and food safety issues.
\end{abstract}

Keywords Food systems $\cdot$ Meshwork $\cdot$ Organizing $\cdot$ Relationality $\cdot$ Self-organizing

\section{Introduction}

In this paper, we develop the concept of meshwork to examine the informal processes of organizing within food systems. In our globally traded food industry, international and national authorities seek to maintain food security and food safety; yet, there is increasing concern that food standards are compromised and food outcomes are inequitable (BlayPalmer et al. 2016; Davey and Richards 2013). Fraudulent production, inadequate safety practices, and negative health and environmental outcomes continue to be associated with industrialized food production and the consumption of highly processed foods (e.g. Asfaw 2011; Baker and Friel 2014; Neate and Moulds 2013; Pollan 2008; van Bommel and Spicer 2011). This is despite attempts to ensure traceability and address issues of food quality, safety, and

Kathryn Pavlovich

kathryn.pavlovich@waikato.ac.nz

Alison Henderson

alison.henderson@waikato.ac.nz

David Barling

d.barling@herts.ac.uk

1 Waikato Management School, Private Bag 3105, Hamilton, New Zealand

2 University of Hertfordshire, Hatfield, Herts AL10 9AB, UK provenance through food regulation and labelling (Barling et al. 2009; Campbell 2009; Henderson 2013; Hoff et al. 2016). Nowhere is the fragility of our food supply chains more evident than in the current COVID-19 environment, with increasing concerns regarding both the length of distribution chains and issues accessing immigrant labour. This means that the timing for a new ontological perspective based upon relationality is important as we participate in new forms of meshing local and global.

Thus, there are increasing calls for a more thoughtful ecological sensibility that recognizes and sustains the integrity and interaction of locally diverse and globally integrated food systems. This would enable ethical production practices, more equitable outcomes for vulnerable agricultural producers, safer distribution processes, and improved health outcomes for consumers (Barling 2007; Carolan 2013; Mason and Lang 2017; Tansey 2013). As consumers and producers respond, locally organized food initiatives (e.g. farmers' markets, food boxes, food rescue, and the Slow Food movement) increasingly interact with hierarchically organized global food systems in a dialectical transformation that builds horizontal (and local) as well as vertical (and global) links (Davies 2005; Gomez and Bouty 2011; McKeon 2015; Stock et al. 2015). This move towards an ecological sensibility extends collective and individual opportunities to think about impacts at a planetary level (Seyfang 2006). 
Despite this growing diversification, and the associated body of literature that documents specific initiatives in "food matters" (e.g. food justice, food sovereignty, and alternative means of production), research examining new ways of organizing within and between food systems lacks appropriate theoretical frameworks to account for a shift away from predominantly hierarchical structures. Blay-Palmer et al. (2016) discuss how knowledge-sharing networks might foster collective action to transform food systems, but provide less detail about how this might be achieved. We contribute to this debate by further unravelling the organizing dynamic within and between food systems through the concept of meshwork. From a meshwork perspective, food system(s) are not discrete entities with fixed boundaries; rather food production, distribution, and consumption exist as fluid and dynamic connectivities, practices, and interactions that comprise lines of flow that are woven and entangled in various relationalities. We therefore place relational connectivity at the core of the meshwork as a reflexive awareness of the nuanced, interconnected layers of meaning inherent in the paradoxes, tensions, and complexities of the lived experiences of organizing. This builds on the findings of Albrecht and Smithers (2018) who demonstrated that the reconnection perspective of local food systems is complex and contingent on individual preferences that go beyond normative assumptions.

Our research question, "How does a meshwork approach contribute to our understanding of the organizing process within and between food systems, and indicate opportunities for positive change?" is considered through a qualitative case study, Out of our own back yard (Ooooby) in Aotearoa New Zealand, an organization that delivers food boxes of primarily organic, fresh and artisan foods from local growers. As such, the Ooooby case study offers a unique example of an organizing initiative that embraces food producers, food distribution, and food consumers to illustrate the complex organizing and relationality of "food matters". In this case study, we abductively and iteratively move between narrative description of our findings and the emergent theoretical framework. Importantly, we contribute to a new understanding of organizing as a potentiality of relational process. From this perspective, organizing is a relational process that always has inherent potential for further reflexive connectivity, and we demonstrate some of the challenges and opportunities inherent in organizing emergent alternative food initiatives.

\section{Organizing through meshwork}

Recent research in organization studies has moved away from considering an organization as a static entity, recognizing that the term organization can refer to a continuing process of change as "becoming", as well as an entity grounded in the action of organizing (Chia 1999; Chia and Tsoukas 2003; Putnam and Nicotera 2010; Accard 2019). Both organization and organizing are therefore considered to be dynamic, emergent processes in which communication plays a significant role (Pavlovich and Henderson 2018). The communicative constitution of organizing thus contributes to sensemaking (Weick and Sutcliffe 2005), may confer authority (Nicotera 2013), and contribute to inscribing the material and structural conditions for agency (Cooren 2006; Gomez and Bouty 2011). The implications of such perspectives of organization in relation to interactions and organizing in complex networks such as food systems demand that we consider how tensions and dissensus are communicated, managed, and negotiated, recognizing that interactions are dynamic and fluid, and involve the consideration of materiality and non-materiality, as well as human agency. Holt and den Hond (2013, p. 1589) claim that despite the "proliferation of organization theories", the phenomenon of organizing needs fuller attention and expression, because the ontological assumptions underlying organizing in dynamic systems remain vague. While current theoretical approaches to organizing provide a vocabulary regarding organizing, they do not foreground and privilege the fluidity and dynamic interactions that underpin how relationality enacts organizing (Holt and den Hond 2013; Wahlin 2015). As Carolan (2015, p. 319) states:

One of the valuable lessons... is to emphasize food's relational underbelly, which is to say that any ontological claim about "it" cannot stop at its compositional materiality...In sum, food-and how/what we feel about "it" and the feelings of care we attribute to "itl- cannot be divorced from the embodied practices, socio- institutional arraignments, and cultural conventions whence it came.

To capture this shadow and informal dynamic of organizing food (the underbelly), we suggest that the concept of meshwork provides an innovative theoretical framework for understanding the weaving together of both self-organizing and hierarchical operating systems (Czarniawska 2013; Hamilton 2012; Ingold 2011), and moves beyond the consideration of food systems as discrete entities. From this perspective, the connectivity in "food matters" comprises complex relationalities that flex and flow (Chia and Tsoukas 2003). The threads in the overall meshwork represent a complexity with a collective quality that cannot be reduced to any constitutive elements (Allen and Brown 2016; Pavlovich 2014), but can be woven together in different ways, with the knots and threads continuously changing, alongside the introduction of new threads in the weave. For example, Wahlin (2015) uses meshwork in relation to a Capital of Culture initiative in Umea, Sweden to examine the 
self-organizing and performative strategizing that developed over the period of the initiative. As Wahlin comments, "the meshwork provides an additional layer of interpretation that goes beyond spatio-temporal artefacts and organizational recipes. Organizing and strategizing are-from a meshwork perspective-simply a never-finished business whose existence illuminates the multifarious options available in creative processes" (p. 62). Meshwork therefore allows for complex conceptualization and examination of ambiguities, tensions, and paradoxes, and acknowledges Latour's (2005) interest in re-assembling the social world. However, Rodon and Silva's discussion of meshwork (2015) examines the infrastructure or "architecture" of self-organising within a complex (health) system. Similarly, Wahlin focuses more on the fluid relationality in the structure of the meshwork, rather than the dynamic processes of becoming and performativity, the entangling and disentangling of knots and threads. Wahlin's use of the term "duality", for example, to describe "enabling" and "constraining" seems at odds with the complexity of the meshwork theoretical lens. We would argue that "enabling" and "constraining" are each mutually implicated in the other, in a dynamic dialectical relationship.

The strength of meshwork over other organizing theories, such as actor-network-theory (ANT) (Latour 2005) and network analysis, is that it places relationality at the very core of the organizing process (Chia 2003; Langley et al. 2013). The organizing potentiality therefore resides in a process orientation that becomes the very fabric of events and actions that constitute our phenomenological world (Morin 2008). Network analysis has been critiqued for focusing simplistically on the relationships between actors in fields of interconnected points as unidimensional, fixed nodes; closed systems that generate knowledge, dependent on nodal density, centrality and structural configurations. Hence, networks do not account for tensions, disruptions and histories, with the nodal dots making "cuts" that interrupt the flow of interconnections rather than following the lines of entanglement (Hicks 2016). Similarly, ANT's "flat ontology" has struggled to conceptualize layers such as complex social structures and agency as it ignores social processes, entrenched power relationships, marginality, multiplicity, and other perspectives (2008; Munir and Jones 2004). ANT too has been at risk of becoming too rigid, culminating in the application of ruthless semiotics to create a reality that is too simple without "sensitivity to complexity" ( $\mathrm{Gad}$ and Jensen 2009, p. 59). Krarup and Blok (2011) have also contended that ANT's tendencies towards radical descriptivism ultimately undercut the uncertainties of social reality, with intangible and ephemeral complexity such as moral codes and social phenomena failing to be acknowledged (Cresswell et al. 2011; Krarup and Blok 2011).

Further, our meshwork approach has shared objectives with other approaches in terms of addressing some of the social factors and dynamics made invisible in more established social theorisation. Bourdieu's theory of habitus takes account of context and experience, attempting to resolve the tensions between structure and agency; however, the focus is on the continuity of stable patterns of behaviour, knowledge, and practice rather than the messy loose ends and entanglements of meshwork. Even the diversity of assemblage research, which places the behaviour of actors and the associated relationalities at its core (Deleuze and Guattari 1987), focuses less on the properties and behaviour of the whole in its examination of the parts.

Our focus, then, is on meshwork as a relational ontology that addresses the processes of emergence and becoming. Meshwork entanglements are conceptualized as multidimensional knots, taking consideration of the more complex ontology required for a more thoughtful, moral and ecological sensibility. Klenk (2018, p. 316) explains that "Life is lived not within the perimeter of the network, but along lines that open even as they get entangled with others". In a meshwork approach, threads within one "system" therefore become intertwined with other threads and knots in other 'systems' to weave a whole world of mutual involvement, continually ravelling (and unravelling) within an overall meshwork to grow or "issue forth" along the interwoven lines of their emergent relationships, histories and future trajectories.

In this paper, we examine how a meshwork lens contributes to a deeper understanding of the emergent processes of organizing within and between dynamic "food matters". Our inter-disciplinary approach moves beyond a simplistic examination of local food initiatives to consider how they are organized through relationality. We contribute to the literature on food systems in global contexts by extending the concept of meshwork to conceptualize the challenges and opportunities faced by emerging forms of organizing food, adding to insights on knowledge sharing (e.g. Blay et al. 2016) and reconnection by small scale producers (e.g. Albrecht and Smithers 2018).

\section{Method}

\section{The Ooooby case study}

As elsewhere in the Western world, Aotearoa New Zealand has a variety of food initiatives in response to challenges within global food contexts. In this paper, we focus on a single case study (Stake 1994), Out of Our Own Backyards (Ooooby) as part of a wider research programme that examines the challenges and opportunities provided by emerging food initiatives. Ooooby delivers food boxes of primarily organic, fresh, and artisan foods from local growers to customers in specific regions of Aotearoa New Zealand (and in 
Sydney, Australia; and Fresno, California, USA); it intends that profits from each local hub remain in the local region and contribute to the development of a healthy, sustainable food supply. Ooooby is one of the emergent food initiatives that uses online software to organize food distribution and is disrupting traditional food distribution systems. Critically, it is also one of the few food distributors that has maintained its delivery service during the 4.5 week COVID-19 lockdown in New Zealand.

Ooooby collects customers' orders and sources the required produce from growers, packs the boxes, and then delivers them to the customer's door. Ooooby puts smallscale farming at the heart of building sustainable ways of organizing food (www.ooooby.org). The aim is to build more integrity for food initiatives within local economies and provide better value for money for the consumer. Ooooby supports local jobs with fair returns to producers (with a $50 \%$ return rather than the standard 30\% from supermarkets); provides fresher food, organic where possible; and reduces the environmental footprint-less packaging, less food waste (picking only the produce that is required), and less food miles (sourcing locally). Ooooby differentiates itself from a franchise way of operating through being an enabler of local food networks. Its purpose is to provide the technology hub, with local communities being empowered to operate their hubs how they see fit. Eian (the Ooooby Software Developer) said:

People don't buy an Ooooby franchise. If they are committed, believe in the mission and they are capable of setting up a hub then the only start-up cost is their own wages. No money comes to us other than the $8 \%$ of revenue administration fee.

Ooooby began operating from a converted shipping container in October 2010 in Auckland, New Zealand with 50 customers, and has delivered more than 180,000 food boxes to 8,000 homes (www.ooooby.org). By early 2016, it had grown to include seven hubs: Auckland/Waiheke Island, Hamilton, Tauranga, Taranaki, and Christchurch (New Zealand), and Sydney (Australia) and Fresno (USA). However, at the time of writing, Ooooby has reduced to four hubs: Auckland and Christchurch (New Zealand), Sydney (Australia) and Fresno (USA). Our case study thus offers us both longitudinal and context variability data.

\section{Collecting and analyzing the data}

We chose a qualitative research design to examine the narratives, living interactions, and meanings of actors who (re) create organizing patterns such that relationships become centre-stage (Cunliffe 2011). This approach involves an examination of the interweaving of relational spaces and connections (Ricoeur 1992) (the threads, knots and "spaces-in-between" in meshwork) and recognizes the "messy" nature of qualitative research (Edwards and Stamou 2016) that seeks to rethink the boundaries of theory development and knowledge sharing. We began this research by contacting the founder of Ooooby in 2015, and he was enthusiastic to work with us on our research. Our data collection comprised a series of semistructured interviews with the Directors, Software Developer, Hub Developer, Hub Managers in Tauranga and Hamilton, and local growers supplying Ooooby. We also conducted second interviews with the Founder and the Managers of the three hubs in Tauranga, Hamilton and Christchurch to document more recent changes in the organizing process and practices. Each interview lasted approximately 70-100 min and involved a conversation about the aims, values, and vision for Ooooby, the challenges and constraints, and the day-to-day policies and practices. We followed Ethics Protocols approved by the university ethics committee; we have used pseudonyms for participants; each interview was audio recorded and transcribed, and we took additional notes during the interviews.

Our method of analysis is abductive and iterative. Abduction involves "reading and re-reading data, looking for "surprises" (Cunliffe and Eriksen 2011, p. 1431). It involves identifying data that is unexpected or paradoxical to develop new theoretical concepts to explain these findings. We began by reading our data for initial themes (Braun and Clarke 2006) that acknowledge the historicity of the data, its contextuality, its biographic content, and its socio-political intentionalitythe content - what was, what is, and what might be (Fine et al. 2003). We engaged with the multiple interpretations and transformative possibilities perceived both by participants and by us as researchers. We then drew on our meshwork theoretical approach to re-consider the data regarding the performance of organizing, the relational sense-making, and the complex materiality of the organizational infrastructures and regulatory regimes. As we worked further with the data we reflected on the intricacy of the meshwork metaphor to understand the relationality of the knots and the "spaces-in-between" that provide the possibility of both constraints and transformative opportunities in this fluid and dynamic food initiative (Carolan 2015). Returning to the data enabled us to gather further insights into how these tensions were played out or resolved (Baxter and Montgomery 1996; Putnam et al. 2014) as we reconceptualized the complex web of interactions that comprise the fabric of entanglements of local, national, and global food production and distribution at play.

\section{Findings and discussion: part one}

\section{Entanglements, knots and threads}

With our purpose being to explain the complexity of organizing food, relational connections are central to our analysis, 
highlighting the call for a more thoughtful relational ontology; an awareness of how organisms relate to each other and to their environment through lived experience (Carolan 2015; Pavlovich 2014). Analysis of our first interviews revealed relational connectivity that became knots of selforganization in the meshwork weave. We conceptualise these knots as evolving entanglements of threads representing common issues, relationalities, and materialities. The purpose of these knots is that they provide commonalities around which organizing occurs. We describe the first, and most significant knot - an ecological sensibility. Eian, (Ooooby Software Developer) summed up his reasons for engaging in an ecological sensibility:

I joined Ooooby for environmental reasons, using less energy to get food from place to place, so lower food miles and a lower carbon footprint. But as I became more involved, I started to think about fair returns for the farmer. I know I could never be a farmer; I can't get up at 5am and work so physically hard like they do. But their prices can be unilaterally changed by supermarkets. "This is how much you will get for your broccoli". I would completely understand if they gave up and got a cushy job in the city. But then there would be no food. So that's an even stronger drive for me now.

Other participants noted similar alignment of values through environmental and social stewardship that contributed to developing this knot. For instance, Rob (Founder of Ooooby) references alignment with an ecological sensibility that includes economic and food quality/safety issues:

The fundamental problem with our food system is that it uses too much energy, it's not fair, there are too many leaks in the supply chain, and it's too easy for people to get squeezed without anyone else in the supply chain knowing about it. Also, the food is flavourless and it's not good for you because it is pumped with all this stuff. It has lost its humanness.

Similar thoughts were expressed by Mary, a Hub Manager, "I remember even as a child that I wanted to be part of something that creates a more fair, just, and environmentally conscious world so I've always been involved in community activities".

These relationships facilitate the formation of a close entanglement, or knot, that characterizes an ecological sensibility (e.g., fair wages for farmers, environmental stewardship, organic food) that contributes to a more thoughtful approach to production processes. We can see from the above quotes how similar values from different relationalities become interwoven as they tangle and flex into a meshed interdependency. The continuing entanglement of these knots can form a stabilizing relational conduit that characterizes the value alignment of the meshwork, in this case an ecological sensibility. Such entanglements demonstrate how these knots act as organizing conduits to bring matters of collective concern together. As Carolan (2016, p. 147) has commented in relation to issues in food studies, "Bringing these care relationships into focus is to therefore enact a more enlivened notion of "value", and make problematic those practices that seek to strip caring relationalities from our understanding of the productive world".

The emergent nature of these relationalities can enhance the development of new connections that can become new threads and lines within the meshwork, as noted by (Donna), a Hub Manager:

We were having discussions with another foodbox when Ooooby came to us. When I sat down and evaluated both the systems, the other one was purely business, commercial, and was all about the science of the food, all about the sugar content in the food... They wouldn't touch organics and told me it was rubbish. Whereas Ooooby was all about local foods, developing local suppliers, and using organics whenever possible. The decision was easy.

Rob continued in discussing this alignment:

Our goal is to be able to resource smaller players into organics and then have a channel to market that is easy and accessible for them so that it works for them to sell to the local market. They need to state their intentions by how they're going to market their product and also how they're going to grow the product, what are the inputs. We definitely don't want to be funding people who are going to go throw all these toxins back in the soil and do the same old thing.

This "value alignment" explains how threads can be suspended from one knot to another. They are continually "becoming" and can grow in complexity as new threads become part of the entanglement or knot. The thread in this case is access to markets and distribution, and the above quote illustrates how, through relationality, the thread becomes woven into the knot. The above quotes also highlight how an ecological sensibility can seek to transform problematic organizing processes as more thoughtful intentions align with the values within the meshwork.

Yet, knots may equally comprise complex relationalities with dissimilar agendas and modes of being that are in conflict with each other, sometimes where a single thread becomes dominant and constricts the knot, limiting the relationalities and new connections that can be formed. For example, supermarket chains with preferred supplier contracts often limit the possibility of local food producers gaining access to larger local markets (Humphrey 2007). To some extent, Ooooby exists to circumvent the possibility of such constricted knots, seeking to fill the 
"spaces-in-between" within globalized food systems, creating new lines, threads, and entanglements.

\section{Becoming: threads, and lines}

Seen as a meshwork, the food system is characterised by evolving entanglements, weaving together to form new knots, and the formation of new lines. While our data illustrated knots of collective concerns, they were formed by independent movement through lines of interaction and travel forming threads in the meshwork. We focus briefly on two, much smaller knots-system autonomy and food surplus - to demonstrate relationality as the movement of threads, and lines.

\section{System autonomy}

One of the aims of Ooooby is to facilitate the development of autonomous food initiatives that are adaptive to local contexts for food resilience. Being autonomous helps local communities self-organize within their local context. To achieve this, relationalities that focus on specific practices, such as financial transparency, enhance local autonomy while also ensuring equity and consistency among the hubs. Rob commented:

We want each hub to have as much autonomy as possible, but we need transparency to ensure that we are a collective. We want our growers to be paid $50 \%$, when the industry average is $30 \%$; the hubs have to show their financials so everyone can benchmark across each other. Everyone's salaries will be available so that some level of equity is apparent.

Autonomy implies that while each hub is independent, there is movement through and among the threads to ensure consistency of practices. Connection among the hubs occurs as knowledge sharing moves from hub to hub through the threads that create the knot of autonomy. To encourage this alignment, Ooooby endeavours to make their infrastructure organizing processes - their lines of flow-transparent. For instance, they ensure everyone knows that they charge the hubs $8 \%$ of revenues that comprise of: $3 \%$ for intellectual property (IP) and software development, $3 \%$ finance and management services, and $2 \%$ marketing.

Eian also spoke about "a self-organizing sort of philosophy", and "working towards our own obsolescence". He commented:

What I would love to see is a way where it is much easier for Ooooby operations to spring up organically with less input from us, where people could very easily access all of the tools that they need so that it becomes very simple to set up the Ooooby hub.
This example (system autonomy) demonstrates how knots were linked and tangled through meshwork interactions between, among and through the various threads. The threads enacted movement along lines of flow, and the knot facilitated consistency among the hubs for local autonomy. Hence, these relationships were messy trails of becoming rather than restricted movements along static connections.

\section{Food surplus}

Our third example is a small knot (food surplus) created from previously dangling threads; that is, relationships that had not yet formed but held the material possibility. In this case, Ooooby often has left over food surpluses that are not sent out in boxes to customers. By creating relationships with charity organizations such as the City Mission, Kaivolution, and Food Rescue to give away this surplus food, these dangling threads could form a knot through these new relationships, which again aligned with meshwork values. As Mary, a Hub Manager stated, this new thoughtfulness is "helping people out who need it". This example illustrates how threads can grow into new spaces, ravelling and unravelling in a dynamic process of weaving and knotting. In this way, relationships can be seen as movement, always emerging, as they cluster and strengthen together along lines of flow-rather than being seen as part of a linear infrastructure such as a network. This emerging knot demonstrates how threads can begin to bundle into new spaces, and how the meshwork can continue to evolve by weaving in dangling threads.

\section{The weave, threads, and yarners}

Our analysis of the first series of interviews also examined the interactions influencing the overall meshwork weave, with two "yarners" emerging that impact on weaving the Ooooby meshwork. Klenk (2018) describes yarning as entanglements that twist the fibre to give it strength and durability, or what we would consider to be meshwork resilience. Again, these entanglements are related to the multiple and diverse points in the weaving of threads and lines in which similar knots emerge from common relationalities. The first yarner we identified was variation and redundancy that acts to twist the weave. With its aim to "reverse local organic food from being the icing on the cake, to being the cake itself" (Rob, Ooooby Founder), Ooooby relies on many local producers. Rob stated, "We [Ooooby] may be the common hub in the middle but we expect the players feeding into it will typically be small scale cottage industry. We want to encourage private local food production". Local food production will vary in local contexts, because it aims to be responsive to local needs. Stemming from this variation in 
the weave of local producers is the notion of redundancy. Rob further explained:

As our hub system is replicated, there will be more support and encouragement for someone who's got a problem to go to multiple places for it to be solved rather than some central middle, central repository of information. We have an example of this happening now. In Auckland, Evelyn is going away on holiday and the Sydney guys are going to cover a lot of her work so we've got this redundancy built in. We've also got training happening so we've got Auckland training Fresno in California. The more hubs we get the more points of support that there are.

These practices demonstrate how the multiple and varied meshwork threads self-organize through positive interpretations of redundancy. The flows along the threads replicate information gathering and sharing by running up and down the lines-with the yarner (variation and redundancy) twisting the overall mesh of the weave. Bergson (1911) claims that such small-scale heterogeneous connectivity creates difference-in-kind, the source of novelty and differentiation. The scope and depth through diversity of producers can provide support for self-organization and resilience through the complexity and fluidity of threads within the weave. Thus, this yarner may strengthen the associated knots and provide resilience in the weave.

We compare this with a more formalised hierarchy that follows a productivist ideology (Lawrence et al. 2013) with a central knot and tight systems and connections between them. This tighter weave is characterized by low cost production, little slack and redundancy, and becomes less resilient to change. The mainstream global food system, involving complex regulations, industrialized food production, long-distance distribution infrastructure, and corporate supermarket chains might be said to provide typical examples of such formal hierarchies. Such tight weaves with little redundancy and flexibility limit the possibilities for large linear supply chains to be responsive to local needs.

The second yarner that impacted on the weave in relation to Ooooby was the low level of regulation. Because most of the produce handled is fresh and whole food, at the outset there was minimal direct regulatory involvement. Rob confirmed:

NZ's regulatory system is pretty relaxed compared to the States and Australia. Plus, we don't process any food so we don't need to comply with any food processing regulations. Mostly, we just handle raw food and there is no actual license required to do that. We are only audited for safe handling practices. Other food, like honey and jam, is packaged and the suppliers have to comply, not us.
One of the suppliers commented, "I am not certified to supply a supermarket; but I don't need anything for the markets and foodboxes". Nevertheless, a Hub Manager, Mary, stated that she personally visits the local growers every year to ensure that they are organic and/or spray-free, implying a personal code of practice and the enactment of relationships that ensure oversight of supplier practice. The low level of regulation infrastructure is thus a yarner that actually enables the strengthening of the meshwork that the Ooooby system is a part of. "I can tell immediately if sprays have been used. We've all got to be honest for the system to thrive", she said.

These yarners-variation and redundancy, and simple regulation-emerge from the multiple and varied threads and knots that twist the weave in various ways. We suggest that for Ooooby, these yarners create a loose weave with multiple relational entanglements - a flat rather than a hierarchical means of organizing - and they are the source of meshwork resilience. The small-scale heterogeneous connections create overlapping functions that in turn create opportunities for both substitution and renewal. The relationality that emerges from this connectivity enhances the resilience of the loose meshwork weave as it supports the transfer of best practice throughout Ooooby through the ongoing movement among meshwork threads.

\section{Findings and discussion: part two}

\section{Changing knots: mesh-work and mesh-ing}

Our second set of interviews gives a longitudinal lens on meshwork relationality, demonstrating how the process of organizing is always an impulse to change (Accard 2019; Ingold 2013), "becoming" something else (Chia and Tsoukas 2003), and temporal (Bakker et al. 2016). Our more recent contact with Ooooby participants suggests that Ooooby meshwork has changed and become less resilient than expected. The Tauranga and Hamilton Ooooby hubs are now "serviced" from the Auckland team and the Taranaki hub is no longer operating; although, Christchurch is still self-sufficient, as are the hubs in Fresno and Sydney. A variety of issues has meant that the smaller local hubs were no longer viable for local producers; they have proven difficult to manage and they have not been able to maintain/grow customer numbers. Effectively, Ooooby has downsized from seven to four hubs, and refocused on hubs in large cities. Ooooby is experiencing the tension between needing to be a hierarchy (Auckland servicing other hubs) and wanting hubs to be self-organizing, autonomous and locally adaptive (as in Christchurch, Fresno and Sydney). There is a stratification process occurring that characterizes consolidation, acknowledging broken threads and a tighter weave that changes the 
meshwork texture. This demonstrates a shift in the meshwork weave, some "unknotting" resulting in loose threads, and the reinforcing of key knots-economies of scale-that are more typical of mainstream food supply systems. The original vision of infinitely replicable, autonomous and self-organizing hubs exists in tension with the materiality of managing supply and demand - not evident in 2015 - and the changing entanglements and relationalities created partly by changes in various material and relational contexts.

Changes in the operating context for Ooooby have proved challenging as the regulation yarner has twisted the weave in a new way-always becoming. The introduction of the Food Act 2014, which came into force on 1 March 2016, represents a change in the "weave" of the regulatory environment for the food system in Aotearoa New Zealand, and demonstrates how the materiality of regulatory demands created mesh-work. Mesh-work is seen as the sometimes arduous, but always reflexive process of weaving together new materialities and relationalities through movement among and between threads. For example, the Act takes a new approach to managing food safety; it requires even small-scale food producers to register as a business, develop a food control plan, and become "verified" if they do not sell directly to the customer; for example, at the farm gate or farmers' market (see https://www.mpi.govt.nz/food-safety/food-act-2014/). This regulatory change is costly and time consuming, meaning that many small, local suppliers selling through Ooooby could not afford to become registered,. The Waikato Hub Manager, Donna, confirmed:

We could only source stuff from registered producers, and for people (suppliers) who were just selling us their surplus it just wasn't going to work. I think when the Food Act came in that was like... oh my gosh... okay, what's next?

Similarly, another Hub Manager, Hannah, commented on how the new regulations created a uniform material context that changed how Ooooby was able to manage supply and demand:

It [The Food Act] was a nightmare; we were panicking that we were going to be doing something illegal. If you are an Ooooby customer, you are getting a box with different things supplied by different people and because it comes through Ooooby, an online retailer basically, we had to comply with the Act.... If you were just delivering produce to a place and packing it in a box you are low risk under the Food Act. But the minute I cut a pumpkin, I go up to risk level three and I have to do one million other things that are very onerous.

This challenged one of the original philosophical premises on which Ooooby was founded: working with small food producers to be responsive to the needs of local communities:

Mesh-work then refers to how the processes of organizing - as becoming and relationality - are enacted for meshing to occur. Such "work" may be either challenging and frustrating or productive and creative, or both. If these processes are fraught, and the work needed creates too much conflict or is too challenging, then the meshwork weave can break down, or the original lines of knots and entanglements continue to privilege specific threads and thus constrain emerging relationalities.

It also became evident that customers used to the continuous availability of globally sourced food expected to be able to customize their weekly food boxes, and hub managers in Taranaki, Tauranga and Hamilton struggled to find sufficient, regular supplies of locally-sourced food that met the individualized demands of their customer base. Paradoxically, as one of the Ooooby Directors, Kevin, commented, "In order to grow the local grower base you've got to have a customer base". The knot related to an ecological sensibility shared by Ooooby hubs was inconsistent with the complex relationalities introduced by growing the customer base, demonstrating broken threads. Rob, confirmed the demise of the Taranaki Hub,

The Taranaki region has very little local food from local farmers, and especially since the advent of the Food Act and the higher regulations farmers were required to comply with. So there was a large increase in freighting charges to supply the food that would often come from Hawkes Bay and similar regions that have significant horticulture production.

Another smaller Hub Manager, Hannah, commented: "we couldn't keep the customers". She described customers whose attitude was:

I would prefer to buy local, especially if it is local or organically grown, local food delivered to my door. But when it comes to what I spend my money on each week, firstly I want what I want. So if you are giving me, in the winter, pumpkin and kale and potatoes and carrots, but my kids like tomatoes, even if they are not in season, I will go and buy tomatoes elsewhere.

The Hamilton Hub Manager, Donna, stated:

We were living the Ooooby dream, but to make that work for a customer base that is large enough to get an income, we either need to go to larger suppliers which may still be local and organic, but then it is not so much "out of our own backyard", but more about going to commercial growers.

Ooooby managers in the smaller hubs also found that the scale of the local hub prevented the financial investment in 
buildings (for example, cool storage), equipment (for example, delivery vans), and personnel (relying on volunteers to cover the hours required for sorting and packing food boxes). As Ingold (2011) comments, in these entanglements of threads and pathways, action emerges from the interplay of forces conducted along the lines of meshwork.

Ooooby knots are based on shared values; the enactment of those values in the processes of organizing that they established demonstrates the relationality that allowed this meshwork to develop and flourish. This involves complementary roles and materialities that mesh together to form a new weave (of threads, lines and knots) within the context of the existing food system(s). When the Ooooby meshwork reached into a "space" to form a new hub, the original intentionality of Ooooby began a process of mesh-ing with this new context, and with suppliers, managers, and customers with different histories and expectations, and different relationalities.

As the initial weaving of threads begins, and knots are encountered that are less flexible, there are meshwork changes. Knots and entanglements can become strengths in meshwork, or can become impenetrable. Hence, the relationality of the mesh-ing is challenging, either through material constraints (number of producers, Food Bill) or because of mismatches in the expectations of customers/ hub managers and volunteers.

The Ooooby initiative has encountered difficulties in integrating its self-organizing features and sensibilities with the existing food system(s) and the emerging hubs have had difficulties maintaining the local autonomy of meshwork set up by the Ooooby initiative. They were not always able to be sufficiently adaptive, or resilient, or locally emergent but relied on the original lines of flow and did not become selfmanaging easily or in a timely manner. This comment from Rob, founder of Ooooby, demonstrated his own resilience and commitment to his vision, despite the sometimes arduous mesh-work, involved:

Look, emotionally it has been an absolute rollercoaster because we never knew what was around the next corner. There have been things come up that we have thought are going to really derail us. And we have managed our way through it... There are definitely nights when, like two nights ago, I woke up with a grip in my chest. You know you just have to wait until the morning comes, when the sun comes up.

The spaces-in-between mainstream food systems thus provide opportunities for weaving new meshwork lines such as when food box delivery initiatives and farmers' markets emerge, or for elaboration (new threads and knots) of the existing meshwork. Organizing and strategizing are thusin a meshwork perspective-always becoming in a multifaceted series of ever-changing entanglements that form new meshwork within the meshwork, weaving an intricate web of potential relationality.

\section{Closing remarks}

This innovative research uses the concept of meshwork to make a unique theoretical contribution to an alternative narrative for food organizing matters. We attend to critiques by Holt and den Hond (2013) and Carolan (2016) to provide research that challenges the ontological assumptions underlying the shadow and informal dynamics of organizing. Our use of meshwork furnishes a complex analysis of relationality in our case study of emerging food initiatives in Aotearoa New Zealand, to consider their interactions at a local level within emerging national contexts. As earlier noted, we are now in a COVID-19 environment, meaning that we need new ontologies that examine how relationalities mesh within potentially fragile food supply chains. Thus, we have placed relational connectivity at the core of a meshwork lens as a thoughtful and reflexive awareness of the nuanced, interconnected layers of meaning inherent in the paradoxes, tensions, and complexities of the lived experiences of organizing (Wahlin 2015). We have identified how meshwork entanglements and knots can be self-organizing, and are constantly ravelling and unravelling. Some may emerge as localised variations like patchwork and are replicated throughout the weave; they may also form entanglements that are independent of each other, or they may be hybrids and embroidered in unique ways, and may never form a tight knot that has any stability. We also illustrated how yarners have impacts on the resilience of the weave, always in relationship, and becoming.

We extend current theories of organizing food beyond human and political concerns to include a broader understanding of socio-cultural impacts and a closer focus on the performance of organizing; for example, through detailed understandings of mesh-work and meshing and how the relationalities of mesh-ing can contribute to a broader ecological sensibility (Seyfang 2006). We have also contributed by demonstrating how entangled relationships in food matters can create a complex ontology of organizing through meshwork knots, threads and weave. When issues of collective concern come together to form knots of stabilizing conduits, the meshwork threads indicate processes of movement and reconnection, while the weave suggests degrees of system resilience. This complex ontology explains how messy entanglements are interwoven and enmeshed, rather than travelling predictably along lines, and demonstrates how the process of organizing is always "becoming" (Ingold 2011). Our research offers a contribution regarding how the organizing of food matters occurs through the relational knots of common concern that can become knowledge-sharing 
processes. As Seyfang (2006) found, in her work on sustainable consumption, this can enhance an ecological sensibility and the enactment of ecological citizenship. We also extend current work, with insights from our meshwork approach into how small producers can organize and enact relationships in ways that create new possibilities for connectivity within existing food systems.

Our research has significant practical implications for Aotearoa New Zealand, a country heavily dependent on primary food exports. It begins to identify the challenges and opportunities that emerging forms of organizing and regulation face, as multiple and interdependent food initiatives interact. Creative engagement with such dynamic organizing and regulatory environments will determine future food policies and the management of specific food production, distribution, and consumption issues. We hope that this research will enable us to map how food initiatives in Aotearoa New Zealand could deliver healthier options and greater food security.

In this particular case study, our findings demonstrate the challenges associated with sourcing sufficient local growers, with managing the boundaries between public and private interests, and with organizing the (crowd, and other) funding and legal entities that underpin each iteration of Ooooby in local regions. At the same time, we highlight the significant opportunities created for mentoring new initiatives, and for sharing expertise, while remaining adaptable to local conditions. A limitation of this paper is our focus on a single case study; yet, we see multiple opportunities for further research using meshwork to highlight integration patterns of hierarchy and self-organization within and across other "food matters" and organizing contexts.

Acknowledgements This research was supported by a grant from the Waikato Management School Contestable Funds. We would also like to thank the editorial team and anonymous reviewers for their thoughtful and encouraging comments.

\section{References}

Accard, P. 2019. Criticality: How changes preserve stability in selforganizing systems. Organization Studies 40 (11): 1613-1629.

Albrecht, C., and J. Smithers. 2018. Reconnecting through local food initiatives? Purpose, practice and conceptions of 'value'. Agriculture and Human Values 35: 67-81.

Allen, M., and S. Brown. 2016. Memorial meshwork: The making of the commemorative space of the Hyde Park 7/7 Memorial. Organization 23 (1): 10-28.

Asfaw, A. 2011. Does consumption of processed foods explain disparities in the body weight of individuals? The case of Guatemala. Health Economics 20 (2): 184-195.

Baker, P., and S. Friel. 2014. Processed foods and the nutrition transition: Evidence from Asia. Obesity Reviews 15 (7): 564-577.

Bakker, R., R. DeFillippi, A. Schwab, and J. Sydow. 2016. Temporary organizing: Promises, processes, problems. Organization Studies 37 (12): 1703-1719.
Barling, D. 2007. Food supply chain governance and public health externalities: Upstream policy interventions and the UK state. Journal of Agricultural and Environmental Ethics 20 (3): 285-300.

Barling, D., R. Sharpe, and T. Lang. 2009. Traceability and ethical concerns in the UK wheat-bread chain: From food safety to provenance to transparency. International Journal of Agricultural Sustainability 7 (4): 261-278.

Baxter, L., and B.M. Montgomery. 1996. Relating: Dialogues and dialectics. New York: Guilford Press.

Bergson, H. 1911. Creative evolution. Trans. A. Mitchell. London: Macmillan.

Blay-Palmer, A., R. Sonnino, and J. Custot. 2016. A food politics of the possible? Growing sustainable food systems through networks of knowledge. Agriculture and Human Values 33: 27-43.

Braun, V., and V. Clarke. 2006. Using thematic analysis in psychology. Qualitative Research in Psychology 3 (2): 77-101.

Campbell, H. 2009. Breaking new ground in food regime theory: Corporate environmentalism, ecological feedbacks and the 'food from somewhere' regime. Agriculture and Human Values 26 (4): 309-319.

Carolan, M. 2013. Reclaiming food security. Abingdon, UK: Routledge.

Carolan, M. 2015. Affective sustainable landscapes and care ecologies: Getting a real feel for alternative food communities. Sustainable Science 10: 317-329.

Carolan, M. 2016. Adventurous food futures: Knowing about alternatives is not enough, we need to feel them. Agriculture and Human Values 33: 141-152.

Chia, R. 1999. A 'Rhizomic' model of organizational change and transformation: Perspective from a metaphysics of change. British Journal of Management 10: 209-227.

Chia, R., and H. Tsoukas. 2003. Everything flows and nothing abides. Process Studies 32 (2): 196-224.

Cooren, F. 2006. The organizational world as a plenum of agencies. In Communication as organizing: Practical approaches to research into the dynamic of text and conversation, ed. F. Cooren, J.R. Taylor, and E. Van Every, 81-100. Mahwah, NJ: Lawrence Erlbaum Associates.

Cresswell, K.M., A. Worth, and A. Sheikh. 2011. Implementing and adopting electronic health record systems: How Actor-Network Theory can support evaluation. Clinical Governance: An International Journal 16: 320-336.

Cunliffe, A.L. 2011. Crafting qualitative research: Morgan and Smircich 30 years on. Organizational Research Methods 1: 647-673.

Cunliffe, A.L., and M. Eriksen. 2011. Relational leadership. Human Relations 64 (11): 1425-1449.

Czarniawska, B. 2013. On meshworks and other complications of portraying contemporary organizing. GRI-rapport 2013: 3. University of Gottenburg.

Davey, S., and C. Richards. 2013. Supermarkets and private standards: Unintended consequences of the audit ritual. Agriculture and Human Values 30: 271-281.

Davies, J. 2005. Local governance and the dialectics of hierarchy, market and network. Policy Studies 26 (3-4): 311-335.

Deluze, G., and F. Guattari. 1987. A thousand plateaus: Capitalism and schizophrenia. London: Althone Press.

Elder-Vass, D. 2008. Searching for realism, structure and agency in Actor Network Theory. The British Journal of Sociology 59: $455-473$.

Edwards, A., and E. Stamou. 2016. Relational approaches to knowledge exchange in social science research. In Working relationally in and across practices: A cultural-historical approach to collaboration, ed. A. Edwards, 265-282. Cambridge: Cambridge University Press.

Fine, M., M.E. Torre, K. Boudin, I. Bowen, J. Clark, D. Hylton, and D. Upegui. 2003. Participatory action research: Within and beyond 
bars. In Qualitative research in psychology: Expanding perspectives in methodology and design, ed. P. Camic, J.E. Rhodes, and L. Yardley, 173-198. Washington, DC: American Psychological Association.

Gad, C., and C.B. Jensen. 2009. On the consequences of post-ANT. Science, Technology, and Human Values 35 (1): 55-80.

Gomez, M.-L., and F.I. Bouty. 2011. The emergence of an influential practice: Food for thought. Organization Studies 32 (7): 921-940.

Hamilton, M. 2012. Meshworking evolutionary intelligences for the human hive. Retrieved from https://integralcity.com/2012/02/20/ meshworking-evolutionary-intelligences-for-the-human-hive-3/.

Henderson, A. 2013. Healthy food, on whose terms? Negotiating new boundaries between food and medicine. New Zealand Sociology 28 (4): 59-79.

Hicks, D. 2016. Reply to comments: Meshwork fatigue. Norwegian Archaeological Review 49 (1): 33-39.

Hoff, A., H. Lelieveldt, and R. van der Does. 2016. A biased rapporteur or politics as usual? Reassessing the balance of interests in the EU food information labelling case. Journal of European Public Policy 23 (2): 296-313.

Holt, R., and F. den Hond. 2013. Sapere aude. Organization Studies 34 (11): 1587-1600.

Humphrey, J. 2007. The supermarket revolution in developing countries: Tidal wave or tough competitive struggle? Journal of Economic Geography 7 (4): 433-450.

Ingold, T. 2011. Being alive: Essays on movement, knowledge and description. London: Routledge.

Klenk, N. 2018. From network to meshwork: Becoming attuned to difference in transdisciplinary environmental research encounters. Environmental Science and Policy 89: 315-321.

Krarup, T.M., and A. Blok. 2011. Unfolding the social: Quasi-actants, virtual theory, and the new empiricism of Bruno Latour. The Sociological Review 59 (1): 42-63.

Langley, A., C. Smallman, H. Tsoukas, and A. Van de Ven. 2013. Process studies of change in organization and management: Unveiling temporality, activity, and flow. Academy of Management Journal 56 (1): 1-13.

Latour, B. 2005. Reassembling the social: An introduction to ActorNetwork-Theory. Oxford, UK: Oxford University Press.

Lawrence, G., C. Richards, and K. Lyons. 2013. Food security in Australia in an era of neoliberalism, productivism and climate change. Journal of Rural Studies 29: 30-39.

Mason, P., and T. Lang. 2017. Sustainable diets: How ecological nutrition can transform consumption and the food system. Abingdon, UK: Routledge.

McKeon, N. 2015. Food security governance: Empowering communities, regulating corporations. New York: Routledge.

Morin, E. 2008. On complexity. Translated by R. Postel. Cresskill, NJ: Hampton Press.

Munir, K.A., and M. Jones. 2004. Discontinuity and after: The social dynamics of technology evolution and dominance. Organization Studies 25 (4): 561-581.

Neate, R. and J. Moulds. 2013. Tesco sales tumble on horsemeat scandal. Retrieved from https://www.guardian.co.uk/business/2013/ jun/05/tesco-sales-fall-horsemeat-scandal.

Nicotera, A.M. 2013. Organizations as entitative beings: Some ontological implications of communicative constitution. In What is an organization? Materiality, agency, and discourse, ed. F. Cooren and D. Robichaud, 66-89. New York: Erlbaum.
Pavlovich, K. 2014. A rhizomic approach to tourism destination evolution and transformation. Tourism Management 41 (1): 1-8.

Pavlovich, K. and A. Henderson. 2018. Creating foodscape resilience through ecologies of care. Paper presented at European Group of Organization Studies, Tallinn, Estonia, July 5-7 July.

Pollan, M. 2008. In defense of food: An eater's manifesto. New York: Penguin Press.

Putnam, L.L., K.K. Myers, and B.M. Gailliard. 2014. Examining the tensions in workplace flexibility and exploring options for new directions. Human Relations 67 (4): 413-440.

Putnam, L., and A. Nicotera. 2010. Communicative constitution of organization is a question: Critical issues for addressing it. Management Communication Quarterly 24 (1): 158-165.

Rodon, J., and L. Silva. 2015. Exploring the formation of a heathcare information infrastructure: Hierarchy or meshwork? Journal of the Association for Information Systems 16 (5): 394-417.

Ricoeur, P. 1992. Oneself as another. Trans. K. Blamey. Chicago: University of Chicago Press.

Seyfang, G. 2006. Ecological citizenship and sustainable consumption: Examining local organic food networks. Journal of Rural Studies 22: 383-395.

Stake, R.E. 1994. Case studies. In Handbook of qualitative research, ed. N.K. Denzin and Y.S. Lincoln, 236-247. Thousand Oaks, CA: Sage.

Stock, P., M. Carolan, and C. Rosin. 2015. Food utopias: Reimagining citizenship, ethics and community. New York: Routledge.

Tansey, G. 2013. Food and thriving people: Paradigm shifts for fair and sustainable food systems. Food and Energy Security 2 (1): 1-11.

van Bommel, K., and A. Spicer. 2011. Hail the snail: Hegemonic struggles in the slow food movement. Organization Studies 32 (12): 1717-1744.

Wahlin, N. 2015. Projective cities: Organizing large cultural development initiatives. In Culture and growth: Magical companions or mutually exclusive counterparts?, ed. B. Lundgren and O. Matiu, 44-68. Sibiu: Lucian Blaga University Press.

Weick, K., and K. Sutcliffe. 2005. Organizing and the process of sensemaking. Organization Science 16 (4): 409-421.

Publisher's Note Springer Nature remains neutral with regard to jurisdictional claims in published maps and institutional affiliations.

Kathryn Pavlovich (Ph.D.) is Professor of Strategic Management at the University of Waikato Management School, Hamilton, New Zealand. Her teaching and research interests include system-level organizing, food organzing, and ethical/contemplative enterprise.

Alison Henderson (Ph.D.) is a Research Associate in Management Communication at the University of Waikato. Her research interests focus on the management of controversial public issues, particularly issues related to food, health, and the environment.

David Barling (Ph.D.) is Professor of Food Policy and Security at the Centre for Agriculture, Food and Environmental Management Research, University of Hertfordshire, UK. 